\title{
C1 compounds shape the microbial community of an abandoned century-old oil exploration well.
}

1 Diego Rojas-Gätjens ${ }^{1}$, Paola Fuentes-Schweizer ${ }^{2,3}$, Keilor Rojas-Jimenez ${ }^{4}$, Danilo Pérez-Pantoja ${ }^{5}$, Roberto

2 Avendaño ${ }^{1}$, Randall Alpízar ${ }^{6}$, Carolina Coronado-Ruíz ${ }^{1} \&$ Max Chavarría1,3,7*

$4 \quad{ }^{1}$ Centro Nacional de Innovaciones Biotecnológicas (CENIBiot), CeNAT-CONARE, 1174-1200 San José

5 (Costa Rica). ${ }^{2}$ Centro de Investigación en electroquímica y Energía química (CELEQ), Universidad de

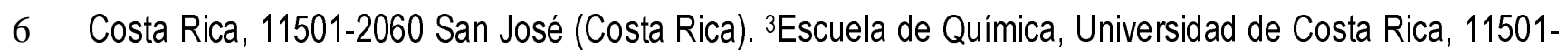

72060 San José (Costa Rica). ${ }^{4}$ Escuela de Biología, Universidad de Costa Rica, 11501-2060 San José

8 (Costa Rica). 5Programa Institucional de Fomento a la Investigación, Desarrollo, e Innovación (PIDi),

9 Universidad Tecnológica Metropolitana, Santiago (Chile). ${ }^{6}$ Hidro Ambiente Consultores, 202, San José

10 (Costa Rica), ${ }^{7}$ Centro de Investigaciones en Productos Naturales (CIPRONA), Universidad de Costa Rica,

11 11501-2060 San José (Costa Rica).

12 Keywords: Methylotrophic bacteria, Methylobacillus, Methylococcus, Methylorubrum, Hydrocarbons,

13 Oil well, Methane, Cahuita National Park

14 Correspondence to: Max Chavarría

15 Escuela de Química \& Centro de Investigaciones en Productos Naturales (CIPRONA)

16 Universidad de Costa Rica

17 Sede Central, San Pedro de Montes de Oca

18 San José, 11501-2060, Costa Rica

19 Phone (+506) 2511 8520. Fax (+506) 22535020

20 E-mail: max.chavarria@ucr.ac.cr 


\section{Abstract}

24 The search for microorganisms that degrade hydrocarbons is highly relevant because it enables the

25 bioremediation of these substances cheaply and without dangerous by-products. In this work, we studied

26 the microbial communities of an exploratory oil well, abandoned a century ago, located in the Cahuita

27 National Park of Costa Rica. Cahuita well is characterized by a continuous efflux of methane and the

28 presence of a mixture of hydrocarbons including C2-dibenzothiophene, phenanthrene or anthracene,

29 fluoranthene pyrene, dibenzothiophene, tricyclic terpanes, pyrene, sesquiterpenes, sterane and n-alkanes.

30 Based on the analysis of $16 \mathrm{~S}$ rRNA gene amplicons, we detected a significant abundance of

31 methylotrophic bacteria (Methylobacillus (6.3-26.0\% of total reads) and Methylococcus (4.1-30.6 \%)) and

32 the presence of common genera associated with hydrocarbon degradation, such as Comamonas (0.8-4.6

$33 \%)$, Hydrogenophaga (1.5-3.3 \%) Rhodobacter (1.0-4.9\%) and Flavobacterium (1.1-6.5 \%). We evidenced

34 the presence of methane monooxygenase (MMO) activities, responsible for the first step in methane

35 metabolism, by amplifying the pmo gene from environmental DNA. We also isolated a strain of

36 Methylorubrum rhodesianum, which was capable of using methanol as its sole carbon source. This work

37 represents a contribution to the understanding of the ecology of communities of microorganisms in

38 environments with permanently high concentrations of methane and hydrocarbons, which also has

39 biotechnological implications for the bioremediation of highly polluting petroleum components.

\section{Introduction}

43 Hydrocarbon pollutants have been declared an environmental issue [1], as a result of their slow

44 biodegradability, genotoxic, mutagenic and cytotoxic activities, especially polycyclic aromatic hydrocarbons 
$45(\mathrm{PAH})$, as well as saturated and unsaturated aliphatic hydrocarbons [2-3]. Hydrocarbon-degrading bacteria

46 have gained importance in recent decades due to their potential in bioremediation and their metabolic

47 versatility. Several studies have been undertaken to understand the mechanisms, paths and composition of

48 bacterial communities involved in the microbial degradation of hydrocarbons [4-7]. Numerous strains with

49 the ability to use these compounds have been isolated and studied; prominent examples are Pseudomonas

50 putida [8-9], Bacillus sp. [10-11, Burkholderia sp. [12-13], Sphingomonas sp. [14] among others [15-17].

51 Even though isolated strains show a fascinating potential under controlled conditions [18-19] most of them

52 failed in field experiments in situ [20-22]. Moreover, culture-dependent techniques (i.e. a study with

53 bacterial isolates) are unable to completely explain the ecology of their habitats. Novel efforts are thus

54 focused on hydrocarbon-degrading bacteria consortia. One way to obtain a general overview of the

55 microbial consortia responsible for degrading hydrocarbons is through culture-independent techniques.

56 Studies with culture-independent techniques have been developed in waters [23-24], soils [25-27], and

57 deep-sea sediments [16,28-29] contaminated with hydrocarbons. Experiments with controlled environments

58 supplemented with multiple oils or biosurfactants [30] have also been conducted. Although these studies

59 are interesting, they have been conducted in environments in which the contact with hydrocarbons was for

60 a brief duration and do not represent accurately the conditions that occur in an oil well in which

61 hydrocarbons are mixed with other carbon sources and gases [31-32]. Few studies have been performed

62 on oil wells; most of them evaluate only the biodegradation capabilities or utilize culture-dependent

63 methods [33-34]. Other studies of oil wells apply to extreme environments with high pressure and

64 temperature, reflecting a community mainly modeled by these physical conditions rather than by the carbon

65 source [35-36]. Therefore, the study of environments where a microbial community is permanently

66 confronted with hydrocarbons and not transiently as occurs in oil spills, is a topic of great interest to

67 understand the ecology and evolution of microorganisms in sites with high concentrations of hydrocarbons

68 as well as for future biotechnological applications. 
70 In this work, based on the analysis of 16S rRNA gene amplicons, we performed an analysis of the microbial

71 communities in an abandoned oil exploration well that dates back almost a century. This oil well is located

72 in Cahuita National Park (for which reason the well is known as Cahuita No 1; Figs. 1a and 1b) in Limón,

73 Costa Rica, which was drilled in 1921 by Sinclair Central American Corporation [37]. This oil well is

74 emblematic in Costa Rican history as it represents an early attempt to obtain oil in the country. After a few

75 years of operation, the efforts to obtain oil ceased; the exploratory oil well was abandoned and has

76 currently become a touristic attraction in a protected zone. Nevertheless, the well was sealed improperly

77 and still expels hydrocarbons and gases to the environment (see Fig. 1c). The few existing records indicate

78 that Cahuita well $N^{0} 1$ has a depth between 1777 [37] and $1922 \mathrm{~m}$ [38] but a complete physicochemical

79 characterization has not be performed yet. The persistence of hydrocarbons and gases in the well for

80 almost 100 years makes it an attractive candidate for an analysis of the microbial composition to

81 understand which organisms are subsisting in a long-term hydrocarbon-providing environment.

82

83 Materials and Methods

84

85 Study Site

86

87 The old oil exploration well (latitude 9.7359', longitude -82.8259॰) is located in Cahuita National Park (Figs.

88 1a and $1 \mathrm{~b})$ in Limón, Costa Rica. The well has a square cement structure with surface area $\sim 9 \mathrm{~m}^{2}$ (Fig. 1c),

89 depth $2.20 \mathrm{~m}$ and is full of water of clear blackish hue. The center of the well that exhibits a continuous

90 bubbling of gas (Fig. 1d, see suppl. video S1) is presumably a narrow hole of depth 1777-1922 m reported

91 in the literature (Castillo, 1961; Pizarro A, 1993). All permissions required for sampling the exploratory oil

92 well were obtained from National System of Conservation Areas (SINAC), Ministry of Environment and 
93 Energy (MINAE) of Costa Rica (resolutions R-SINAC-PNI-ACLAC-013-2019, R-SINAC-PNI-ACLAC-007-

942020 and R-SINAC-PNI-ACLAC-022-2020) and Commission of Biodiversity of University of Costa Rica

95 (resolution $\mathrm{N}^{0}$ 147).

96

97 Sampling and field measurements

98

99 Three sampling campaigns were conducted in this work. In the first campaign (2019 June), nine water

100 samples (each $1 \mathrm{~L}$ ) were collected in sterile glass bottles at various points on the surface of the $9 \mathrm{~m}^{2}$ well.

101 Those nine samples were pooled into three composite samples (codes SW1, SW2, SW3; SW means

102 surface water). In the second campaign (2019 August), nine samples (each $1 \mathrm{~L}$ ) were taken from the center

103 of the well along the depth of the cement structure, specifically three water samples from the surface

104 (pooled and named SW4), three water samples at depth $1 \mathrm{~m}$ (pooled and named W1M; i.e. water $1 \mathrm{~m}$ ) and

105 three water samples at depth $2.20 \mathrm{~m}$ (pooled and named W2M; i.e. water $2 \mathrm{~m}$ ). For analysis of $16 \mathrm{~S}$ rRNA

106 gene amplicons, some samples were processed in duplicate, so indicated in the name R1 (replica 1) or R2

107 (replica 2). Multiple attempts were made to introduce a probe into the main borehole (i.e. the hole of depth

108 1777-1922 m), but it seems that, over time, this narrow hole has become obstructed by sediments and

109 various materials, which allow only the exit of gases or liquids. In the field, the temperature and dissolved

110 oxygen (DO) were measured in water samples with a dissolved-oxygen meter (Model 85, Yellow Springs

111 Instrument Company Inc, Ohio, USA). Water samples for both chemical and microbial analysis were

112 collected using sterile glass bottles and were immediately transported to the laboratory and stored at $4^{\circ} \mathrm{C}$

113 until processing. For sediment sampling, masses between 10 and $50 \mathrm{~g}$ were placed in sterile centrifuge

114 tubes $(50 \mathrm{~mL})$. Sediments (SED1 and SED2) were gathered in the area indicated in Fig. 1c, a few $\mathrm{cm}$ after

115 the well drain to the estuary. The sediments were collected at depths not exceeding $15 \mathrm{~cm}$. Gas samples

116 were collected into a bag (Flexfoil@, cat 262-01, SKC, USA) assisted with a plastic funnel and a grab air- 
117 bag sample pump (cat 222-2301, SKC, USA). In the third campaign (July 2020) five samples from the

118 superficial water were taken specifically for microbial isolation.

120 Measurements of physicochemical parameters

122 The content of calcium, iron, magnesium, potassium, sodium, phosphorus, alkalinity, and total sulfur was

123 analyzed for all samples following Standard Methods for the Examination of Water and Wastewater

124 (SMWW) described by APHA (2017) [39]. The total and partial alkalinity were measured according to APHA

125 (2017) (method 2320B) [39]. The $\mathrm{pH}$ of the water samples was measured with a pH meter (Mettler Toledo

126 Seven compact duo S213, Columbus, Ohio, USA). The conductivity of the samples was measured with a

127 conductivity meter (Mettler Toledo Seven compact duo S213, Columbus, Ohio, USA). The probe was

128 calibrated with a standard solution of known conductivity. The metals were analysed based on APHA

129 standards (method 2320B, Waltham, MA, USA) with atomic absorption (ICP-OES, Perkin Elmer, model

130 Optima 8300, MA, USA). Spectrophotometric determination of ammonium, nitrate and ureic nitrogen

131 concentrations were made in triplicate (10 mL per sample) following QuickChem ${ }^{\circledR}$ methods $10-107-$

132 04-1-A, 10-107-06-2-0 and 31-206-00-1-A respectively in a flow-injection analyzer (FIA, LACHAT

133 QuickChem 8500 Series 2, Mill Rd, WI, USA). Before samples in each batch were analyzed, calibration

134 curves were prepared for each analyte. All analyses were performed at Agronomical Research Center -

135 University of Costa Rica (CIA-UCR) and Center for Electrochemistry and Chemical Energy (CELEQ-UCR).

137 Analysis of hydrocarbons and gases

139 The extraction and qualitative determination of hydrocarbons were performed according to the method 140 described by the European Normalization Committee (2009) [40]. Liquid-liquid extraction (sample $20 \mathrm{~mL}$ ) 
141 with three portions of dichloromethane (each $20 \mathrm{~mL}$ ) was performed. The extract was eluted with a funnel

142 and sodium sulfate and then concentrated using a rotary evaporator initially, followed by a flow of nitrogen

143 to volume $500 \mu \mathrm{L}$. From that volume, $50 \mu \mathrm{L}$ was extracted and eluted in a second alumina column

144 previously deactivated with hexane $(7 \mathrm{~mL})$. A gas chromatograph (Agilent Technologies, model 7890B, CA,

145 USA) with a capillary column (Agilent Technologies, HP-5-MS, $30 \mathrm{~m} \times 0.25 \mathrm{~mm} \times 0.25 \mu \mathrm{m}, \mathrm{CA}$, USA),

146 coupled to a mass spectrometer (MS, Agilent Technologies, model 5977, CA, USA) with helium UAP

147 carrier gas (flow rate $1.1 \mathrm{~mL} / \mathrm{min}$ ) was used to perform the analysis. The temperature of the oven was

148 maintained at $42{ }^{\circ} \mathrm{C}$ for $1.30 \mathrm{~min}$ and then a ramp $\left(5.5^{\circ} \mathrm{C} / \mathrm{min}\right)$ was applied until $300^{\circ} \mathrm{C}$. The data were

149 analyzed (MSD ChemStation program, version E.02.00.493). For the SCAN mode method, a range 50-450

$150 \mathrm{u}$ was employed. Methanol was measured with a gas chromatograph (Agilent Technologies, model 7890B,

151 CA, USA) with an analytical column (DB-WAX, Agilent Technologies, $30 \mathrm{~m} \times 0.25 \mathrm{~mm} \mathrm{ID} \times 0.25 \mu \mathrm{m}$ ) and

152 measured simultaneously with both a flame-ionization (FID) and MS detector. The chromatograph was

153 operated with a temperature ramp $\left(50^{\circ} \mathrm{C}\right.$ for $5 \mathrm{~min}$ and then at $25^{\circ} \mathrm{C} / \mathrm{min}$ to $\left.160^{\circ} \mathrm{C}\right)$; the detector and the

154 injector were set at $280^{\circ} \mathrm{C}$. Argon served as carrier gas $(4.0 \mathrm{~mL} / \mathrm{min})$. Highly pure standards were used

155 (methanol Sigma Aldrich CAS 180 67-56-1). The composition of the gas (specifically the content of

156 methane, ethane, nitrogen, oxygen, carbon oxide and carbon dioxide) was measured with a gas

157 chromatograph (Hewlett Pachard, 6890, CA, USA) equipped with a PLOT fused silica column (GS-Gaspro,

158 Agilent Technologies, $30 \mathrm{~m} \times 0.32 \mathrm{~mm}$ ) and both thermal-conductivity (TCD) and FI detectors. The

159 chromatograph was operated with a temperature ramp (from $60^{\circ} \mathrm{C}$ for $6 \mathrm{~min}$ and then at $25^{\circ} \mathrm{C} / \mathrm{min}$ to 260

$\left.160{ }^{\circ} \mathrm{C}\right)$. The injector and detector temperatures were both $250^{\circ} \mathrm{C}$; argon served as carrier gas $(4.5 \mathrm{~mL} / \mathrm{min})$.

161 Certified standard gas (Agilent Technologies, type refinery gas, capacity $1 \mathrm{~L}$, pressure 30 psig at $21^{\circ} \mathrm{C}$,

162 batch number 112PLU1SPC10D, CA, USA) served as a standard for accuracy. All analyses were 163 performed at CELEQ-UCR. 
DNA Extraction and 16 S rRNA gene sequencing

166

167 Samples were processed as described previously [41] with some modifications. Briefly, each sample was

168 filtered individually through a vacuum system under sterile conditions using a sterile membrane filter (pore

169 size $0.22 \mu \mathrm{m}$, GV CAT No GVWP04700, Millipore, Darmstadt, Germany). The filters were collected and

170 stored at $-30^{\circ} \mathrm{C}$ until processing, and then cut into small pieces using sterile surgical scissors. The DNA

171 was extracted with a DNA isolation kit (PowerSoil $\cap$, MoBio, Carlsbad, CA, USA) as described by the

172 manufacturer; half a filter was used for each extraction. Cell lysis was accomplished in one step of bead

173 beating (FastPrep-24, MP Biomedicals, Santa Ana, CA, USA) for $40 \mathrm{~s}$ at $6.0 \mathrm{~m} / \mathrm{s}$. To process the

174 sediments, a representative sample of mass $500 \mathrm{mg}$ (obtained with vortex homogenization and then

175 through grid sampling) was collected from $10-50 \mathrm{~g}$ of each wet sediment; DNA was extracted according to

176 the same protocol. For the construction of the microbial amplicon library (16S rRNA), the V4 hypervariable

177 region was PCR-amplified with universal primers 515F and 806R [42]. The PCR-generated products were

178 subjected to a 250 nt paired-end sequencing (Illumina MiSeq, Novogene Bioinformatics Technology Co.,

179 Ltd, CA, USA).

180

181 Bioinformatic analysis of 16 S rDNA amplicon data

183 Sequences were quality check and analyzed using version 1.12 of the DADA2 pipeline [43]. Briefly, reads

184 were quality-filtered, deduplicate and Amplicon Sequence Variant (ASV), a higher-resolution analogue of

185 the traditional Operational Taxonomic Unit (OTU) were inferred. Finally, chimeric sequences and global

186 singletons were removed. This process resulted in an amplicon sequence variant (ASV) table, which

187 records the number of times each exact amplicon sequence variant was observed in a sample. The

188 taxonomic assignment was performed on comparing sequences against the SILVA reference database 
189 v132 [43] and then curated on comparing sequences against the GenBank database of NCBI. Global

190 singletons were removed. After these processes, we obtained 2,561,563 sequences and 6993 ASV. The

191 average number of sequences per sample was 197,043 , ranging from 181,657 to 225,244 . The sequence

192 data were deposited in the sequence-read archive (SRA) of GenBank under the BioProject ID

193 PRJNA614582. The statistical analyses and their visualization were performed with the $\mathrm{R}$ statistical

194 program [45] and Rstudio interface. Package Vegan v2.5-6 [46] was used to calculate alpha-diversity

195 estimators (Shannon and Simpson indexes), non-metric multi-dimensional scaling analyses (NMDS). Data

196 tables with the ASV abundances were normalized into relative abundances and then converted into a

197 Bray-Curtis similarity matrix. The differences of the oxygen concentration (See Table 1) on the bacterial

198 community composition were evaluated with non-parametric multivariate analysis of variance

199 (PERMANOVA) and paimise PERMANOVA (adonis2 function with 999 permutations), taking into

200 consideration 3 groups: superficial (0 meters), subsuperficial (1-2 meters) and sediments.

202 Methane monooxygenase (MMO) detection

204 For determining the presence of the enzyme Methane Monooxygenase (MMO) a section of the gene pmo 205 was amplified using primers PmoC374 (AGCARGACGGYACNTGGC) and PmoA344 206 (ANGTCCAHCCCCAGAAGT) described by Ghashghavi et al. [48]. Due to the degenerate nature of 207 primers selected, the polymerase chain reaction (PCR) was performed on a Mastercycler ep Gradient S 208 thermal cycler (Eppendorf, Hamburg, Germany) using a slow ramp in temperature $\left(0.1^{\circ} \mathrm{C} \mathrm{s}-1\right)$ between the 209 annealing and extension cycles, as described by Luton et al. [49]. A negative control was prepared with all 210 components of the PCR reaction except the DNA sample. PCR products were analyzed on $2 \%$ agarose 211 gels using standard protocols. For sequencing a unique visible band in the agarose gel of $\sim 700$ bp was 212 excised using a sterile bistoury and purified using GeneJET Gel Extraction Kit (Thermo Scientific ${ }^{T M}$, USA). 
213 Finally, PCR products were sequenced using BigDye Terminator v3.1 cycle sequencing kit and cleaned

214 with BigDye XTerminator Purification kit (Applied Biosystems, USA). Products were analysed on a 3130xl

215 Genetic Analyzer (Applied Biosystems, USA). Forward and Reverse sequences were assembled using

216 Bioedit. Nucleotide sequence was deposited on the GenBank database under accession number

217 MT948143.

Isolation, identification, and phylogenetic analysis of methylotrophic bacteria

221 Water samples (1L) from the well were filter using a sterile membrane filter (pore size $0.22 \mu \mathrm{m}$, GV CAT No

222 GVWP04700, Millipore, Darmstadt, Germany). The filters were collected and then resuspended in Dorn

223 mineral medium [50] with methanol $25 \mathrm{mM}$ as a sole source of carbon and energy. A dense $20 \mathrm{~mL}$ culture

224 was obtained after 3 days of incubation at $30^{\circ} \mathrm{C}$ in fluted $100 \mathrm{~mL}$ Erlenmeyer flasks on a rotary shaker (180

$225 \mathrm{rpm})$. A $20 \mu \mathrm{L}$ aliquot of this culture was successively transferred by three times into fresh medium. Lastly,

$22650 \mu \mathrm{L}$ of the culture was plated on Dorn mineral medium agar plates containing methanol as the sole

227 carbon source $(25 \mathrm{mM})$. One of the fastest growing colonies was picked and streaked on the same agar

228 medium. Purity was checked on R2A agar (Merck KGaA, Darmstadt, Germany) plates and the ability to use

229 methanol as sole carbon and energy source was again checked in liquid mineral medium.

231 For identification by $16 \mathrm{~S}$ rRNA gene sequencing, a small inoculum of the bacteria was added to the

232 Polymerase chain reaction (PCR) mixture. PCR and sequencing protocol were made as described above

233 using the primers $27 \mathrm{~F}$ and 1492R [51]. The obtained sequence was compared to the 16S rRNA

234 bacterial/Archaeal database of the NCBI using blast. Nucleotide sequence was deposited on the GenBank

235 under accession number MT936438. For phylogenetic analysis, the closest 16S rRNA sequences from 236 validly described microbial type strains and isolates were retrieved by blastN against the curated 16S rRNA 
237 database. The sequences were aligned using MUSCLE [52]. These alignments enabled phylogenetic

238 reconstruction with MEGA6 software [53] and the maximum-likelihood method based on the general time-

239 reversible model. In total, 1000 bootstrap replications were calculated to ensure the robustness of the

240 results.

241

242 Bacterial growth using methanol as its sole carbon source

244 Growth curves were performed to evaluate the ability of the bacterial isolate to use methanol as the sole

245 carbon source. First, bacterium was striked in solid M9 mineral medium supplemented with $25 \mathrm{mM}$ of

246 methanol as its sole carbon source. Then a preinoculum of the bacterium was growth for $48 \mathrm{~h}$ in $\mathrm{M} 9$

247 mineral medium with $25 \mathrm{mM}$ of methanol. Later, the culture was diluted to an initial optical approximately

$248 \quad 0.05$ at $600 \mathrm{~nm}$ in fresh M9 mineral medium containing methanol as its sole carbon source $(25 \mathrm{mM})$.

249 Bacterial growth was estimated on monitoring the optical density at $600 \mathrm{~nm}$ (Synergy H1 Hybrid Multi-Mode

250 Reader, Biotek, Winooski VT, USA) over 4 independent replicates of cultures in plates (96 wells; Nunclon

251162 TM Surface; Nunc A/S, Roskilde, Denmark). Plates were incubated at $30^{\circ} \mathrm{C}$ for $48 \mathrm{~h}$ with continuous

252 orbital shaking at $180 \mathrm{rpm}$; the optical density was measured every $5 \mathrm{~min}$.

254 Results and Discussion

255

256 Physicochemical analysis of Cahuita well No 1

258 The major physical-chemical properties of the oil well samples are presented in Table 1. The data revealed 259 that Cahuita well $\mathrm{N}^{0} 1$ presented a pH neutral to slightly alkaline (7.0-8.0) and corresponds to a dysoxic 
260 environment $(0.63-0.90 \mathrm{mg} \mathrm{O} / \mathrm{L}$, Table 1) according to terminology proposed by Tyson and Pearson

261 (1991) [54]. The chemical analyses revealed the presence of nitrate, typically found in most fresh and sea

262 water as well as urea-nitrogen and ammonium. The latter two chemical forms of nitrogen are associated

263 with organic material; their presence in the oil well is reasonable in view of the reducing environment of

264 these sites, the presence of vegetation and the influence of sea water [55]. The concentrations of calcium,

265 magnesium, potassium, iron and sulfur are in the ranges accepted for freshwater according to the Costa

266 Rican Institute of Water and Sewers (AyA) [56]. The concentration of sodium and the conductivity

267 measurements indicate that fresh and sea water are present in combination in the sampled site. (see Table

268 1). This condition is likely due to the fact that the oil well is near the coast (Fig. 1b), and seawater seeps

269 through the ground until it reaches the well, increasing the values of these parameters.

271 As mentioned above, Cahuita well $N^{0} 1$ shows a constant efflux of gases rising from the center of the well

272 (Fig. 1d, see Supplementary Video S1). GC-analysis shows that the gas is mostly methane (Supplementary

273 Fig. S1). Other gases such as ethane, $\mathrm{N}_{2}, \mathrm{O}_{2}, \mathrm{CO}$ and $\mathrm{CO}_{2}$ were not detected. Previously, it has been

274 reported that most oil wells are also sources of natural gas, mainly comprising methane (Alvarez et al.

275 2018; Zavala-Araiza et al. 2015). Other C1 compounds such as methanol were not detected (limit of 276 detection $80 \mathrm{mg} / \mathrm{L}$ or $2.5 \mathrm{mM})$.

278 Various hydrocarbons were also identified in all samples (see Fig. 2). Samples taken during the first

279 sampling (SW1, SW2, SW3) contained C2-dibenzothiophene, phenanthrene or anthracene, fluoranthene,

280 dibenzothiophene, tricyclic terpane, pyrene, sesquiterpenes, sterane and n-alkanes. In the second

281 sampling (samples SW4, W1M and W2M), only C2-dibenzothiophene and steranes were found. We

282 suggest that the absence of most hydrocarbons in the second sampling could be due to high tide, which 283 dilutes these products in the soil and the oil well. Other simple aromatic compounds commonly known as 
284 BTEX (benzene, toluene, ethylbenzene and xylene) were not identified in any sample. Nevertheless, C2-

285 dibenzothiophene was identified in all samples, and during the low tide n-alkanes, steranes and

286 sesquiterpenes were all present. PAH (including C2-dibenzothiophene) are important pollutants of the

287 environment because of their extremely cytotoxic, genotoxic and mutagenic activity and slow

288 biodegradability [57]. Aliphatic and polycyclic saturated hydrocarbons are also important contaminants of

289 the environment because they readily diffuse in soil and subterranean water reservoirs [58]. These results

290 indicate that the samples from an exploratory oil well contain hydrocarbons and pollutant gases of

291 significant importance for the environment in a complicated mixture that provide a broad array of carbon

292 sources for microbial communities.

293

294 Analysis of microbial communities

295

296 The bacterial community in Cahuita N¹ oil well showed a high diversity (Shannon-index > 3) (see

297 Supplementary Fig. S2) and multiple phylotypes. In total, 6993 ASV were identified, of which phylum

298 Proteobacteria was most abundant, representing 60.6 to $79.2 \%$ of the sequences in samples (see Fig. 3a).

299 Within this group Betaproteobacteria represented on average $29.4 \%$ of the sequences,

300 Gammaproteobacteria 19.9\%, Alphaproteobacteria $20.2 \%$ and Deltaproteobacteria $2.0 \%$. Other phyla

301 were detected in smaller average proportions, such as Bacteroidetes (4.4 - 11.2\%), Firmicutes (0.5-18.5

$302 \%)$, Candidate Patescibacteria (1.7-15.6 \%), Actinobacteria (2.5-6.4 \%) and Chloroflexi (0.4-4.6 \%) (Fig.

303 3a).

304

305 Further analysis of the microbial communities revealed that the dominant families correspond to 306 methylothropic bacteria (Methylophilaceae, Methylococcaceae; 15.7-53.4 \%) (see Fig. 3b). Families such 307 as Burkholderiaceae (5.7-13.2 \%), Rhodobacteracea (4.5-25.6 \%) and Flavobacteraceae (2.6-6.5 \%) were 
308 also identified with an abundance greater than $2.5 \%$ in more than one sample. These families have been

309 associated with hydrocarbon degradation in contaminated soil and water [13-59-60], governing most of

310 their communities in previous studies. Notably, the family Pseudomonaceae was not an abundant member

311 of the community even though it has been identified as an important hydrocarbon degrader, with a critical

312 role as biosurfactant of hydrocarbons [61].

313

314 Abundant ASVs detected in our samples encompass members of the genera Comamonas,

315 Hydrogenophaga, Flavobacterium, Novosphingobium and Terrimonas (see Fig. 4), bacteria from these taxa

316 have been reported to degrade oil in multiple environments. Particularly they have been related to PAH-

317 contaminated habitats and their biodegradation [62-63], therefore suggesting that they obtain its energy by

318 consuming and degrading the PAHs present in the oil well, ie. dibenzothiophene, phenanthrene,

319 anthracene and pyrene (see Fig. 2). Additionally, previous reports demonstrated that some strains of

320 Comamonas and Hydrogenophaga can degrade saturated and unsaturated alkanes in situ and ex situ

$321[62,64]$. These ASV have hence likely adapted to the consumption of various hydrocarbons for almost 100

322 years, making them attractive candidates for isolation. Future work is required to understand the

323 interactions between these bacteria that have co-evolved to degrade hydrocarbons in multiple and

324 complicated sources.

326 Even though common hydrocarbon consumers were present in the oil well with abundance $>1 \%$, the

327 environment was controlled mainly by C1-consuming bacteria (see Fig. 4), specifically

328 Methylobacillus_ASV01 (6.3-26.1\% of total reads) and Methylococcus_ASV02 (4.1-30.0\% of total reads).

329 These bacteria are the protagonists in carbon recycling in the trophic chain, performing an essential role in

330 the conversion of $\mathrm{CH}_{4}$ to $\mathrm{CO}_{2}$. Methylotrophs are characterize for oxidizing $\mathrm{C} 1$ compounds such as

331 methane, methanol, and methylamine to the central intermediate formaldehyde. The by-products might be 
332 assimilated for anabolism or proceed to the electron chain, consequently, to produce ATP [65]. The ability

333 of these genera to metabolize methane and methanol could hence also participate in the re-coupling of $\mathrm{C1}$

334 compounds to the trophic chain.

336 According to our data Methyloccoccus_ASV02 is an abundant member of the community (4.1-30.0\%).

337 Members of these genera have been reported to oxidize methane using a soluble or a membrane methane

338 monooxygenase (MMO), an enzyme of which the biological function is to transform methane to methanol

339 [66]. Notwithstanding this effect, this enzyme presents unspecific activity and has the ability to oxidize other

340 hydrocarbons of a longer chain [67]; however, to our knowledge there is no study that demonstrate

341 Methylococcus growth with these substrates. The unspecific activity of MMO attributed to Methyloccocus

342 and other methane-oxidizing bacteria have an important potential role in the bioremediation of

343 hydrocarbons, specifically short-chain n-alkanes [68-69].

345 Another important ASV found was Methylobacillus_ASV01 which encompass the majority of the sequences

346 classified as these genera. Members of the family Methylophilaceae, where the genus Methylobacillus is

347 found, lack the ability to metabolize methane, but they have been reported to be able to use other $\mathrm{C} 1$

348 compounds, such as methanol, methylamine and formaldehyde, as a carbon source [70]. Methylobacillus

349 has been found in petroleum-contaminated soils, specifically in experiments of PAH biodegradation in vitro

350 [71], therefore whether they can grow using hydrocarbons as a carbon source is at present unclear. Our

351 chemical analyses revealed that methane is the major gas in the oil well (see Supplementary Fig. S1);

352 other $\mathrm{C} 1$ compounds such as methanol were not detected (data not shown; limit of detection for methanol

$3532.5 \mathrm{mM})$. We hence suggest that a cross-feeding might occur between different genera such as

354 Methylococcus_ASV02 and Methylobacillus_ASV01, i.e. Methylococcus oxidizes methane to methanol,

355 and Methylobacillus uses the methanol that leaks for its growth. The rapid consumption of methanol by 
356 these bacteria might explain its absence at levels greater than $2.5 \mathrm{mM}$ in the samples. Similar cross-

357 feeding essential for bacterial survival has been reported in an oil-degrading synthetic consortium, which

358 allows bacteria to survive [72].

360 Additionally, Non-metric multidimensional scaling (NMDS) and PERMANOVA were consistent in showing 361 significant differences $(p=0.004$ ) between the communities belonging to the superficial water, sub362 superficial water and the sediments (Fig. 5). Hydrocarbon-degrading bacteria and their metabolic paths

363 have been shown to differ among aerobic, anaerobic waters and sediments polluted with hydrocarbons [21,

$36424,35,75]$. Even though these differences appear in the PERMANOVA, there is no clear difference on

365 analysis of the most abundant groups of the samples (see Fig. 3). The variation in the microbial

366 communities in the water samples might be due to a slight oxygen gradient present between the superficial

$367(0.90 \mathrm{mg} \mathrm{O} / \mathrm{L}, 13.2 \%$ of oxygen saturation) and the sub-superficial samples $(0.63 \mathrm{mg} \mathrm{O} / \mathrm{L}$ corresponding

368 to $6.7 \%$ of oxygen saturation) (see Table 1). This condition might avoid the growth of some 369 microorganisms with metabolisms sensitive to oxygen changes. In contrast, the sediments presented a 370 distinct community because of the volatilization of some hydrocarbons and the accumulation of other oil 371 compounds.

373 In order to validate the results obtained by $16 \mathrm{~S}$ rRNA gene amplicons and confirm the importance of the C1

374 metabolism in this abandoned oil well, we decided to use two approaches: first, identify genes responsible

375 for methane metabolism in the environmental DNA and second isolate methylotrophic bacteria. For the first

376 approximation, we amplify a region of pmo gene which encodes for the methane monooxygenase, an

377 enzyme responsible for the oxidation of methane to methanol. As seen in Supplementary Fig. S3, we were

378 able to amplify a band of approximately $700 \mathrm{bp}$, by performing PCR with degenerate primers previously 379 used to amplify a region of the pmo gene. The sequencing of this DNA fragment (GenBank Accession: 
MT948143) confirms the presence in our samples of a gene that encodes a methane monooxygenase

381 closely related to the enzyme reported in Methylococcus capsulatus genome (GenBank Accession:

382 AE017282.2) (93.3\% similarity), reaffirming the importance of this genus and its byproducts in the pathways

383 taking place in this abandoned oil well.

385 On the other hand, for the isolation of methylotrophic bacteria, we try to isolate microorganisms capable of 386 using methane and methanol as the only carbon source. After various efforts, we could not isolate 387 methane-consuming bacteria (data not shown), but we were able to isolate and identify a methanol388 consuming bacterium. The strain isolated was a pink-pigmented bacterium which show the ability to use 389 methanol as its sole carbon source in solid and liquid media (See Figs. 6a-6c). According to the $16 \mathrm{~S}$ rRNA 390 gene sequence the strain was classified as a Methylorubrum rhodesianum which is known as a facultative 391 methylotrophic bacterium with the ability to use methanol and methylamine [73]. Phylogenetic analysis

392 revealed that $M$. rhodesianum isolated in this work is closely related to the strain obtained from a 393 formaldehyde enrichment experiment (Fig. 6d) [74]. Interestingly our strain shows a very slow growth in rich 394 media such as R2A and LB (data not shown) suggesting that this strain prefer C1 compounds such as the 395 methanol possibly generated by other bacteria in the oil well. The isolation of bacteria capable of growing 396 solely on methanol reaffirms the importance of $\mathrm{C} 1$ compounds in shaping the microbial community in the 397 abandoned oil well. In summary, this system is governed by methylotrophic bacteria and some common 398 hydrocarbon degraders (see Fig. 4), indicating that the community in the oil well is modeled primarily by C1 399 carbon sources and indicating a community metabolism in which hydrocarbon biodegradation might be 400 coupled with methane metabolism through enzyme specificity or cross-feeding (Fig. 7). 
404 This is the first chemical and microbiological analysis of the abandoned oil well Cahuita $N^{0} 1$, which has

405 been a focus of pollution in Cahuita National Park for about 99 years. The chemical analysis shows that the

406 Cahuita oil well is characterized by a continuous efflux of methane and the presence of hydrocarbons

407 including C2-dibenzothiophene, phenanthrene or anthracene, fluoranthene pyrene, dibenzothiophene,

408 tricyclic terpene, pyrene, sesquiterpenes, sterane and n-alkanes in a complicated mixture. The microbial

409 community in the oil well is dominated by methylotrophic bacteria (e.g.

410 Methylobacillus, Methylococcus and Methylorubrum) and other common hydrocarbon degraders

411 (Burkholderia, Rhodobacter and Flavobacterium). Our results show that the community is governed by a

412 C1 metabolism, conditioned by the methane expelled by the oil well (Fig. 7). The enduring contamination

413 makes this habitat of great interest for bioremediation purposes, including the isolation of novel

414 hydrocarbon-degrading bacteria long-term adapted to complex mixtures of these compounds. Future work

415 is required to obtain more bacterial isolates and to understand the whole biochemical reactions occurring in

416 this abandoned oil well.

418 References

420 1. WHO (1983) Polynuclear aromatic compounds, Part 1, chemical, environmental and experimental

421 data. IARC Monogr. Eval. Carcinog. Risk Chem. Hum. 32:1-453

422 2. Mastrangelo G, Fadda E, Marzia V (1996) Polycyclic aromatic hydrocarbons and cancer in man.

423 Environ Health Perspect 104:1166-1170. https://doi.org/ 10.1289/ehp.961041166

424 3. Cerniglia CE (1992) Biodegradation of polycyclic aromatic hydrocarbons. Biodegradation 3:351425 368. https://doi.org/10.1007/BF00129093 
426 4. Agulló L., Pieper DH, Seeger M. (2017) Genetics and biochemistry of biphenyl and PCB

427 biodegradation. In: Rojo F. (eds) Aerobic utilization of hydrocarbons, Ooils and lipids. Handbook of 428 Hydrocarbon and Lipid Microbiology. Springer, Cham. pp 1-28

429 5. Krell T, Lacal J, Guazzaroni ME et al (2012) Responses of Pseudomonas putida to toxic aromatic 430 carbon sources. J Biotechnol 160:25-32. https://doi.org/10.1016/j.jbiotec.2012.01.026

$431 \quad 6 . \quad$ Van der Meer JR, de Vos WM, Harayama S, Zehnder AJ (1992) Molecular mechanisms of genetic

432 adaptation to xenobiotic compounds. Microbiol Rev 56:677-694

433 7. Xu X, Liu W, Tian S et al (2018) Petroleum hydrocarbon-degrading bacteria for the remediation of 434 oil pollution under aerobic conditions: a perspective analysis. Front Microbiol 9(2885). 435 https://doi.org/10.3389/fmicb.2018.02885

436 8. Jiménez JI, Miñambres B, Garcia JL, Diaz E (2002) Genomic analysis of the aromatic catabolic 437 pathways from Pseudomonas putida KT2440. Environ Microbiol 4:824-841. https://doi.org/10.1046/j.1462-

$438 \quad 2920.2002 .00370 . x$

439 9. Nikel PI, Chavarría M, Danchin A, de Lorenzo V (2016) From dirt to industrial applications:

440 Pseudomonas putida as a synthetic biology chassis for hosting harsh biochemical reactions. Curr Opin

441 Chem Biol 34:20-29. https://doi.org/10.1016/j.cbpa.2016.05.011

442 10. Mukherjee AK, Bordoloi NK (2012) Biodegradation of benzene, toluene, and xylene (BTX) in liquid

443 culture and in soil by Bacillus subtilis and Pseudomonas aeruginosa strains and a formulated bacterial

444 consortium. Environ Sci Pollut Res 19:3380-3388. https://doi.org/10.1007/s11356-012-0862-8

445 11. Wang D, Lin J, Lin J, Wang W, Li S (2019) Biodegradation of petroleum hydrocarbons by Bacillus 446 subtilis BL-27, a strain with weak hydrophobicity. Molecules 24:3021.

447 https://doi.org/10.3390/molecules24173021

448 12. Johnson GR, Olsen RH (1997) Multiple pathways for toluene degradation in Burkholderia sp. strain 449 JS150. Appl Environ Microbiol 63:4047-4052 
450 13. Kim TJ, Lee EY, Kim YJ, Ryu HW (2003) Degradation of polyaromatic hydrocarbons by

451 Burkholderia cepacia 2A-12. World J Microb Biot 19:411-417. https://doi.org/10.1023/A:1023998719787

452 14. Liu Y, Zhang J, Zhang Z (2004) Isolation and characterization of polycyclic aromatic hydrocarbons-

453 degrading Sphingomonas sp. strain ZL5. Biodegradation 15:205-212.

454 https://doi.org/10.1023/b:biod.0000026579.38741.e1

455 15. Yuan J, Lai Q, Sun F, Zheng T, Shao Z (2015) The diversity of PAH-degrading bacteria in a deep-

456 sea water column above the Southwest Indian Ridge. Front Microbiol 6(853).

457 https://doi.org/10.3389/fmicb.2015.00853

458 16. Liu J, Zheng Y, Lin H et al (2019) Proliferation of hydrocarbon-degrading microbes at the bottom of 459 the Mariana Trench. Microbiome 7(47). https://doi.org/10.1186/s40168-019-0652-3

460 17. Lumactud $\mathrm{R}$, Fulthorpe $\mathrm{R}$, Sentchilo $\mathrm{V}$ et al (2017) Draft genome sequence of Microbacterium 461 foliorum strain 122 isolated from a plant growing in a chronically hydrocarbon-contaminated site. Genome 462 Announc 5(21): e00434-17. https://doi.org/10.1128/genomeA.00434-17

463 18. Pizarro-Tobías P, Niqui J.L, Roca A, Solano J, Fernández M, Bastida F, García C, Ramos J.L 464 (2014) Field trial on removal of petroleum-hydrocarbon pollutants using a microbial consortium for 465 bioremediation and rhizoremediation. Environ Microbiol Rep 7:85-94. https://doi.org/10.1111/1758$466 \quad 2229.12174$

467 19. Arau S, Oliveira D, Pegorin S et al (2019) Characterization of novel hydrocarbon-degrading 468 Gordonia paraffinivorans and Gordonia sihwensis strains isolated from composting. PLoS One 469 14:e0215396. https://doi.org/10.1371/journal.pone.0215396

470 20. Lee $Y$, Lee $Y$, Jeon CO (2019) Biodegradation of naphthalene, BTEX, and aliphatic hydrocarbons 471 by Paraburkholderia aromaticivorans BN5 isolated from petroleum-contaminated soil. Sci Rep 9(860). 472 https://doi.org/10.1038/s41598-018-36165-x 
473 21. Saul DJ, Aislabie JM, Brown CE, Harris L, Foght, JM (2005) Hydrocarbon contamination changes

474 the bacterial diversity of soil from around Scott Base, Antarctica. FEMS Microbiol Ecol 53:141-155.

$475 \quad$ https://doi.org/10.1016/j.femsec.2004.11.007

476 22. Xu X, Liu W, Tian S et al (2018) Petroleum hydrocarbon-degrading bacteria for the remediation of

477 oil pollution under aerobic conditions: a perspective analysis. Front Microbiol 9(2885).

478 https://doi.org/10.3389/fmicb.2018.02885

479 23. Zakharenko A.S, Galachyants Y.P, Morozov I.V et al (2019) Bacterial communities in areas of oil

480 and methane seeps in pelagic of Lake Baikal. Microb Ecol 78(2):269-285. https://doi.org/10.1007/s00248-

$481 \quad 018-1299-5$

482 24. Lamendella R, Strutt S, Borglin S et al (2014) Assessment of the deep water horizon oil spill impact

483 on Gulf coast microbial communities. Front Microbiol 5(130). https://doi.org/10.3389/fmicb.2014.00130

484 25. Yang Y, Wang J, Liao J, Xie S, Huang Y (2014) Distribution of naphthalene dioxygenase genes in

485 crude oil-contaminated soils. Microb Ecol 68:785-793. https://doi.org/10.1007/s00248-014-0457-7

486 26. Liu Q, Tang J, Gao K, Gurav R, Giesy JP (2017) Aerobic degradation of crude oil by 487 microorganisms in soils from four geographic regions of China. Sci Rep $7(14856)$.

488 https://doi.org/10.1038/s41598-017-14032-5

489 27. Zhou HW, Guo CL, Wong YS, Tam NFY (2006) Genetic diversity of dioxygenase genes in

490 polycyclic aromatic hydrocarbon-degrading bacteria isolated from mangrove sediments. FEMS Microbiol

491 Lett 262:148-157. https://doi.org/10.1111/j.1574-6968.2006.00379.x

492 28. Dong X, Greening C, Rattray JE et al (2019) Metabolic potential of uncultured bacteria and 493 archaea associated with petroleum seepage in deep-sea sediments. Nat Commun 10(1816). 494 https://doi.org/10.1038/s41467-019-09747-0 
495 29. Gontikaki E, Potts LD, Anderson JA et al (2018) Hydrocarbon-degrading bacteria in deep-water

496 subarctic sediments (Faroe-Shetland Channel). J Appl Microbiol 125:1040-1053.

497 https://doi.org/10.1111/jam.14030

498 30. Adrion AC, Singleton DR, Nakamura, Shea D, Aitken MD (2016) Improving polycyclic aromatic

499 hydrocarbon biodegradation in contaminated soil through low-level surfactant addition after conventional

500 bioremediation. Environ Eng Sci 33:659-670. https://doi.org/10.1089/ees.2016.0128

501 31. Gold T, Soter S (1982) Abiogenic methane and the origin of petroleum. Energ Explor Exploit 1:89-

502 104. https://doi.org/10.1177/014459878200100202

503 32. Larter S. R, Head I. M, Huang H, Bennett B, Jones M, Aplin A.C, Murray A, Erdmann M, Wilhelms

504 A and Di Primio R (2015) Biodegradation, gas destruction and methane generation in deep subsurface

505 petroleum reservoirs: an overview. Petroleum Geology Conference Series 6:633-639.

506 https://doi.org/10.1144/0060633

507 33. Xiong S, Li S, Chen J, Zhao L, Zhang H, Zhang X (2015) Crude oil degradation by bacterial

508 consortia under four different redox and temperature conditions. Appl Microbiol Biotechnol 99:1451-1461.

509 https://doi.org/10.1007/s00253-014-6042-7

510 34. Yu C, Yao J, Cai M et al (2014) Polycyclic aromatic hydrocarbons degrading microflora in a tropical

511 oil-production well. Bull Environ Contam Toxicol 93:632-636. https://doi.org/10.1007/s00128-014-1371-x

512 35. Yamane K, Hattori Y, Ohtagaki H, Fujiwara K (2011) Microbial diversity with dominance of 16S

513 rRNA gene sequences with high GC contents at 74 and $98^{\circ} \mathrm{C}$ subsurface crude oil deposits in Japan.

514 FEMS Microbiol Ecol 76:220-235. https://doi.org/10.1111/j.1574-6941.2011.01044.x

515 36. Beeder J, Torsvik T, Lien T (1995) Thermodesulforhabdus norvegicus gen. nov., sp. nov., a novel 516 thermophilic sulfate-reducing bacterium from oil field water. Arch Microbiol 164:331-336. 
517 37. Pizarro AD (1993) Los pozos profundos perforados en Costa Rica: Aspectos litologicos y

518 bioestratigraficos. Revista Geológica de América Central 15:81-85. http://doi.org/

519 10.15517/RGAC.V0115.13240

520 38. Castillo R (1975) Sinopsis histórica sobre las exploraciones petroleras en Costa Rica. Revista de

521 la Universidad de Costa Rica 41:47-62.

522 39. APHA (2017) Standard methods for the examination of wastewater, American Public Health

523 Association. (23rd ed) Washington DC.

524 40. European Normalization Committee (2009) Oil spill identification - Waterborne petroleum and

525 petroleum products - Part 2: Analytical methodology and interpretation of results based on GC-FID and 526 GC-MS low resolution analyses.

527 41. Arce-Rodríguez A, Puente-Sánchez F, Avendaño R et al (2017) Pristine but metal-rich Río Sucio 528 (Dirty River) is dominated by Gallionella and other iron-sulfur oxidizing microbes. Extremophiles 21:235-

529 243. https://doi.org/10.1007/s00792-016-0898-7

530 42. Caporaso JG, Lauber C.L, Walters WA, Berg-Lyons D, Lozupone CA, Tumbaugh PJ, Fierer N, 531 Knight R (2010) Global patterns of 16S rRNA diversity at a depth of millions of sequences per sample. Proc

532 Natl Acad Sci USA 108:4516-4522. https://doi.org/10.1073/pnas.1000080107

533 43. Callahan BJ, McMurdie PJ, Rosen MJ, Han AW, Johnson AJA, Holmes SP (2016) DADA2: High-

534 resolution sample inference from Illumina amplicon data. Nat Methods 13:581-583.

535 https://doi.org/10.1038/nmeth.3869

536 44. Quast C, Pruesse E, Yilmaz P, Gerken J, Schweer T, Yarza P, Peplies J, Glöckner FO (2013) The

537 SILVA ribosomal RNA gene database project: improved data processing and web-based tools. Nucleic

538 Acids Res 41:590-596. https://doi.org/10.1093/nar/gks1219

539 45. R-Core-Team (2019) R: A language and environment for statistical computing. Retrieved from 540 https://www.r-project.org/ 
541 46. Oksanen J, Blanchet FG, Friendly M et al (2019) Vegan: community ecology package. R package

542 version 2.5-6. Retrieved from https://cran.r-project.org/package=vegan

543 47. Cambronero-Heinrichs JC, Matarrita-Carranza B, Murillo-Cruz C et al (2019). Phylogenetic

544 analyses of antibiotic-producing Streptomyces sp. isolates obtained from the stingless-bee Tetragonisca

545 angustula (Apidae: Meliponini). Microbiology 165:292-301. https://doi.org/10.1099/mic.0.000754

546 48. Ghashghavi M, Jetten M, Lüke C (2017). Survey of methanotrophic diversity in various ecosystems

547 by degenerate methane monooxygenase gene primers. AMB Express 7(1):162.

$548 \quad$ https://doi.org/10.1186/s13568-017-0466-2

549 49. Luton PE, Wayne JM, Sharp RJ, Riley PW (2002) The mcrA gene as an alternative to $16 \mathrm{~S}$ rRNA in

550 the phylogenetic analysis of methanogen populations in landfill. Microbiology 148:3521-3530.

$551 \quad$ https://doi.org/10.1099/00221287-148-11-3521

552 50. Dorn E, Hellwig M, Reineke W, Knackmuss HJ (1974) Isolation and characterization of a 3-

553 chlorobenzoate-degrading Pseudomonad. Arch Microbiol 99:61-70

554 51. Mao D, Zhou Q, Chen C, Quan ZX (2012) Coverage evaluation of universal bacterial primers using

555 the metagenomic datasets. BMC Microbiol 12(66). https://doi.org/10.1186/1471-2180-12-66

556 52. Edgar RC, Drive RM, Valley M (2004) MUSCLE: multiple sequence alignment with high accuracy

557 and high throughput. Nucleic Acids Res 32:1792-1797. https://doi.org/10.1093/nar/gkh340

558 53. Tamura K, Stecher G, Peterson D, Filipski K, Kumar S (2013) MEGA6: Molecular evolutionary

559 genetics analysis version 6.0. Mol Biol Evol 30:2725-2729. https://doi.org/10.1093/molbev/mst197

560 54. Tyson R, Pearson T (1991) Modern and ancient continental shelf anoxia: an overview. Geological

561 Society, London, special publications 58:1-24. https://doi.org/10.1144/GSL.SP.1991.058.01.01

562 55. Silver M, Knöller K, Schlögl J, Kübeck C, Schüth C (2018) Nitrogen cycling and origin of

563 ammonium during infiltration of treated wastewater for managed aquifer recharge. App Geochem 97:71-80.

564 https://doi.org/10.1016/j.apgeochem.2018.08.003 
565 56. La Gaceta. (2005) Decreto No 32327-S El Presidente de la República y la Ministra de Salud.

566 57. Lin C, Chen S, Huang K, Lee W, Lin W, Tsai J, Chaung H (2008) PAHs, PAH-induced carcinogenic

567 potency, and particle-extract-induced cytotoxicity of traffic-related Nano/Ultrafine particles. Environ Sci

568 Technol 42:4229-4235. https://doi.org/10.1021/es703107w

569 58. Truskewycz A, Gundry T. D, Khudur L.S, Kolobaric A, Taha M, Aburto-Medina A, Ball AS,

570 Shahsavari E (2019) Petroleum hydrocarbon contamination in terrestrial ecosystems-fate and microbial

571 responses. Molecules 24:3400.

572 59. Amund OO, Teniola OD, Olatope SO (2007) Microbial degradation of petroleum hydrocarbons in a

573 polluted tropical stream. World J Microbiol Biotechnol 23:1149-1159. https://doi.org/10.1007/s11274-007-

$574 \quad 9345-3$

575 60. Pujalte J, Lucena T (2014) The Family Rhodobacteraceae. In: Rosenberg E, DeLong EF, Lory S et 576 al (eds) The Prokaryotes. Springer, Berlin, Heidelberg https://doi.org/10.1007/978-3-642-30197-1_377

577 61. Wu T, Xu J, Xie W, Yao Z, Yang H, Sun C, Li X (2018) Pseudomonas aeruginosa L10: A 578 hydrocarbon-degrading, biosurfactant-producing, and plant-growth-promoting endophytic bacterium 579 isolated from a reed (Phragmites australis). Front Microbiol 9(1087).

580 https://doi.org/10.3389/fmicb.2018.01087

581 62. Aburto A, Peimbert M (2011) Degradation of a benzene - toluene mixture by hydrocarbon adapted

582 bacterial communities. Ann Microbiol 61:553-562. https://doi.org/10.1007/s13213-010-0173-6

583 63. Han X., Liu Y, Zheng $Y$ (2014). Response of bacterial pdo1, nah, and C120 genes to aged soil

584 PAH pollution in a coke factory area. Environ Sci Pollut Res 21:9754-9763. https://doi.org/10.1007/s11356-

$585 \quad 014-2928-2$

586 64. Goyal AK, Zylstra GJ (1997) Genetics of naphthalene and phenanthrene degradation by 587 Comamonas testosteroni. J Ind Microbiol Biotechnol 19:401-407. 
588 65. Whittenbury R, Dalton H. (1981) The Methylotrophic Bacteria. In: Starr MP, Stolp H, Trüper HG et

589 al (eds) The Prokaryotes. Springer, Berlin, Heidelberg pp 894-902. https://doi.org/10.1007/978-3-662-

590 13187-9_71

591 66. Sirajuddin S, Rosenzweig AC (2015) Enzymatic oxidation of methane. Biochemistry 54: 2283-

592 2294. https://doi.org/10.1021/acs.biochem.5b00198

593 67. Patel RN, Hou CT, Laskin Al, Felix A (1982) Microbial Oxidation of hydrocarbons: Properties of a

594 soluble methane monooxygenase from a facultative methane- utilizing organism, Methylobacterium sp.

595 strain CRL-26. Appl Environ Microbiol 44:1130-1137.

596 68. Lee S, Keeney DR, Lim D, Dispirito A, Semrau JD (2006) Mixed pollutant degradation by

597 Methylosinus trichosporium OB3b expressing either soluble or particulate methane monooxygenase: can

598 the tortoise beat the hare? Appl Environ Microbiol 72:7503-7509. https://doi.org/10.1128/AEM.01604-06

599 69. Semrau JD (2011) Bioremediation via methanotrophy: overview of recent findings and suggestions

600 for future research. Front Microbiol 2(209). https://doi.org/10.3389/fmicb.2011.00209

601 70. Doronina N, Kaparullina E, Trotsenko Y (2014) The Family Methylophilaceae. In: Rosenberg E,

602 DeLong EF, Lory S et al (eds) The Prokaryotes. Springer, Berlin, Heidelberg pp. 869-880.

603 71. Lu C, Hong Y, Liu J, Gao Y, Ma Z, Yang B, Ling W, Waigi MG (2019) A PAH-degrading bacterial 604 community enriched with contaminated agricultural soil and its utility for microbial bioremediation. Environ 605 Pollut 251:773-782. https://doi.org/10.1016/j.envpol.2019.05.044

606 72. Piccardi P, Vessman B, Mitri S (2019) Toxicity drives facilitation between 4 bacterial species. Proc

607 Natl Acad Sci USA 116:15979-15984. https://doi.org/10.1073/pnas.1906172116

608 73. Green P, Ardley J (2018) Review of the genus Methylobacterium and closely related organisms: a 609 proposal that some Methylobacterium species be reclassified into a new genus, Methylorubrum gen. nov.

610 Int J Syst Evol Microbiol. 68(9). https://doi.org/10.1099/ijsem.0.002856 
611 74. Green PN, Bousfield IJ, Hood D. (1988) Three new Methylobacterium species: M. rhodesianum sp.

612 nov., M. zatmanii sp. nov., and M. fujisawaense sp. nov. Int J Syst Bacteriol. 38:124-127

613 75. da Cruz G, de Vasconcellos SP, Angolini CFF, Dellagnezze BM, Garcia I, de Oliveira VM, Neto E,

614 Marsaioli AJ (2011) Could petroleum biodegradation be a joint achievement of aerobic and anaerobic

615 microorganisms in deep sea reservoirs? AMB Express 1:47. https://doi.org/10.1186\%2F2191-0855-1-47

616

617 Acknowledgements

618

619 We are grateful for the support of park rangers at Cahuita National Park and the SINAC administration and

620 to Arnoldo Vargas and José Jimenez for assistance in the design of some figures.

621

\section{Author contributions}

624 CCR and MC conceived and designed the experiments; DRG, RA, RAI, PF, DP-P performed the

625 experiments; DRG, PF, MC, KR analyzed the data; PF, DP-P MC contributed reagents or materials or 626 analytical tools; DRG, PF, KR, MC wrote the paper. All authors reviewed and approved the final version of 627 the manuscript.

\section{Competing financial interests}

631 The authors declare no competing financial interests.

\section{Funding}


635 The Vice-rectory of Research of Universidad de Costa Rica (project number 809-B8-518) and Centro

636 Nacional de Innovaciones Biotecnológicas (CENIBiot) supported this research. D.P.-P. also thanks the

637 support of Chilean government through Grants ANID PIA/Anillo ACT172128, ANID PIA/BASAL FB0002

638 and FONDECYT 1201741.

639

640 Availability of data and material

641

642 All sequences obtained in this study are available at BioProject ID PRJNA614582 and GeneBank 643 accession numbers MT948143 and MT936438.

\section{Captions of figures}

648 Fig. 1 Exploratory oil well at Cahuita, Limón, Costa Rica. A) This exploratory oil well is located at the

649 Caribbean coast of Costa Rica in Cahuita National Park. B) The exploratory oil well is located beside

650 Suarez River. The red star shows the exact location. C) The well was drilled in 1921; a cement base about

$6513 \times 3 \mathrm{~m}$ was built. As seen in the figure, the well has an oily appearance and is slightly darker than normal

652 waters. The red arrow shows where contaminated water drains to the soil and then to the river. The

653 sediments were taken from the contaminated soils. D) From the surface of the well a constant efflux of gas 654 occurs. 
656 Fig. 2 Hydrocarbons detected in the oil well. The thermal map shows the absence (grey) and presence

657 (yellow) of each hydrocarbon analyzed in the water samples. The most representative ion used in the 658 detection of each compound in the mass spectrometer is indicated along the abscissa axis.

660 Fig. 3 Taxonomic composition of the oil-well waters and contaminated sediments Relative

661 abundance of bacterial and archaeal organisms at the A) phylum and B) family level. The ASV were 662 taxonomically classified using SILVA reference database v132 [44], as described in Materials and Methods.

663 The superficial water samples are identified as SW1R1 to SW4R2. Sub-superficial water samples are 664 identified as W1MR1 to W2MR2. Sediment samples are identified as SED1 and SED2.

666 Fig. 4 Thermal map representing the most abundant ASV in each sample. This map depicts the 667 percentage of $16 \mathrm{~S}$ rRNA gene sequences assigned to each ASV (ordinate axis) across the 13 samples 668 analyzed (abscissa axis).

670 Fig. 5 Non-metric multidimensional scaling analysis of the prokaryotic communities in the Cahuita

671 oil well. A clustering of communities according to the oxygen content of the samples (See Table 1) and to 672 the habitat (water column versus sediment) is shown. The NMDS and the Permanova analyses were 673 performed with Package Vegan v2.5-6 [47].

675 Fig. 6 Isolation of Methylorubrum rhodesianum, a methylotrophic bacterium present in the

676 abandoned oil well. A) Methylorubrum rhodesianum C1 culture in solid M9 mineral medium with methanol

$677(25 \mathrm{mM})$ as its sole carbon source after $48 \mathrm{~h}$. B) Colonies are small and present a characteristic pink color.

678 C) Growth curve of Methylorubrum rhodesianum $\mathrm{C} 1$ in $\mathrm{M} 9$ minimal media with methanol $25 \mathrm{mM}$ as its sole 679 carbon source, the curve was performed as described in material and methods. D) Phylogenetic tree of 
680 Methylorubrum rhodesianum C1, with close related microorganisms. The phylogenetic reconstruction was

681 made using MEGA as described in Materials and Methods.

682

683 Fig. 7 Cartoon of the biochemical processes and microorganisms involved in Cahuita N01 oil well.

684 The results indicate that the microbial community is dominated by microorganisms capable of using $\mathrm{C} 1$

685 compounds. Methane, possibly of abiotic origin, is oxidized in the first instance by microorganisms of genus

686 Methylococcus. The methanol produced can then be used by microorganisms of genus Methylobacillus and

687 other facultative methylotrophs such Methylorubrum. Other microorganisms capable of using other

688 hydrocarbons were also identified.

690 Tables

691 Table 1. Physical properties and chemical composition of the abandoned exploratory oil well. ND: Not

692 detected. NM: Not measured.

\begin{tabular}{|c|c|c|c|c|c|c|}
\hline Parameter/element & SW1 & SW2 & SW3 & SW4 & W1M & W2M \\
\hline $\mathrm{pH}( \pm 0.1)$ & 7.5 & 7.4 & 6.9 & 7.9 & 8.0 & 8.0 \\
\hline Oxygen $/ \% \pm 0.01$ & NM & NM & NM & 12.10 & 13.20 & 6.76 \\
\hline Ammonium $/ \mathrm{mg} \mathrm{L}^{-1} \pm 0.1$ & 2.0 & 2.0 & 1.4 & 2.4 & 2.4 & 2.4 \\
\hline Nitrate $/ \mathrm{mg} \mathrm{L}^{-1} \pm 0.005$ & 0.100 & 0.200 & 0.200 & 0.100 & 0.100 & 0.100 \\
\hline Ureic nitrogen $/ \mathrm{mg} \mathrm{L}^{-1} \pm 0.005$ & 0.100 & 0.100 & 0.100 & 0.100 & 0.100 & 0.100 \\
\hline Calcium $/ \mathrm{mg} \mathrm{L}^{-1} \pm 2$ & 42 & 43 & 41 & 26 & 25 & 26 \\
\hline Magnesium $/ \mathrm{mg} \mathrm{L}^{-1} \pm 2$ & 17 & 16 & 16 & 10 & 10 & 11 \\
\hline Potassium $/ \mathrm{mg} \mathrm{L}^{-1} \pm 2$ & 19 & 24 & 22 & 7 & 8 & 8 \\
\hline Phosphorus /mg L ${ }^{-1} \pm 0.01$ & ND & ND & ND & 0.10 & ND & ND \\
\hline
\end{tabular}




\begin{tabular}{|l|l|l|l|l|l|l|}
\hline Iron $/ \mathrm{mg} \mathrm{L}^{-1} \pm 0.01$ & ND & ND & ND & 0.10 & 0.10 & 0.10 \\
\hline Sodium $/ \mathrm{mg} \mathrm{L}^{-1} \pm 40$ & $\mathrm{NM}$ & $\mathrm{NM}$ & $\mathrm{NM}$ & 780 & 788 & 781 \\
\hline Sulfur $/ \mathrm{mg} \mathrm{L}^{-1} \pm 0.05$ & 0.70 & 0.30 & 0.40 & 0.80 & 0.90 & 1.60 \\
\hline Alkalinity /mg L & & & & & & \\
\hline
\end{tabular}

694

695

696

697

698

699

700 


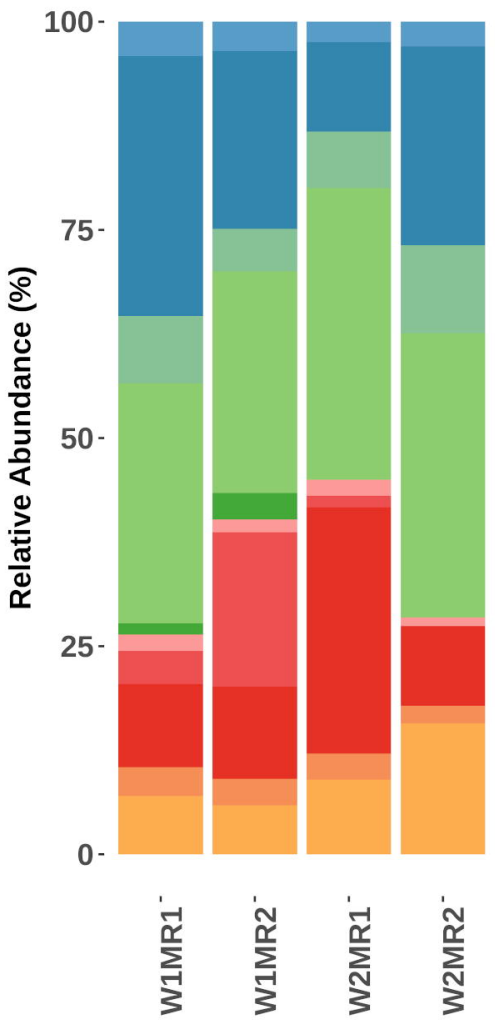

B
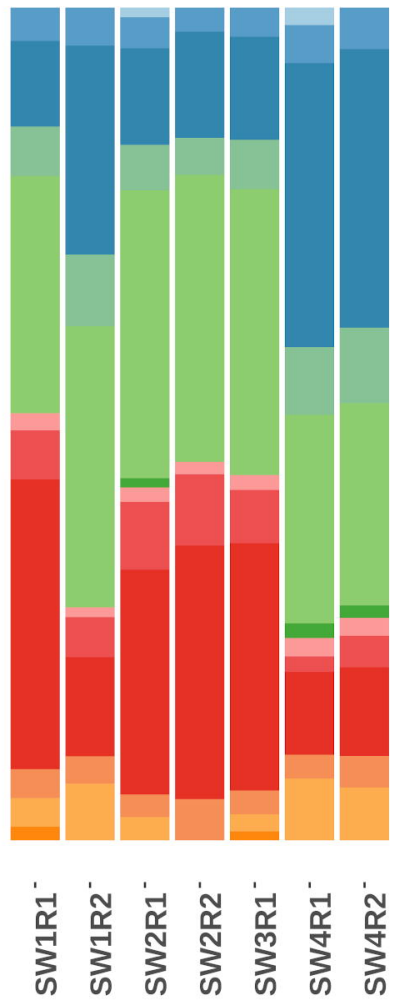

Sample

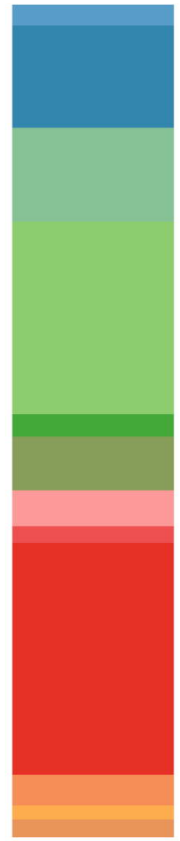

'ั

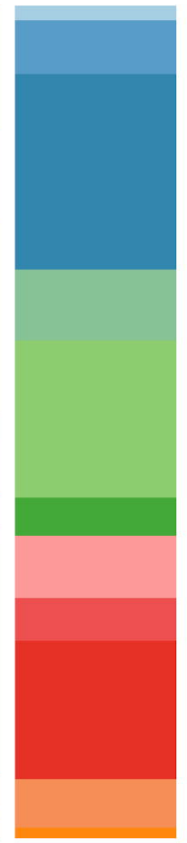

นิ
Superficial

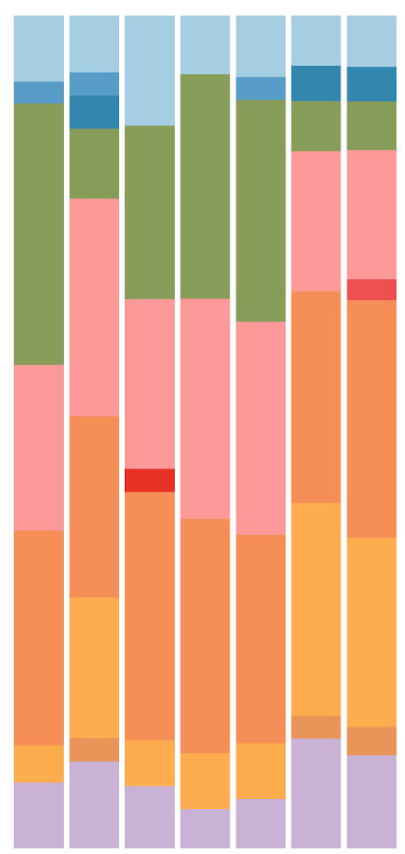

Sediments
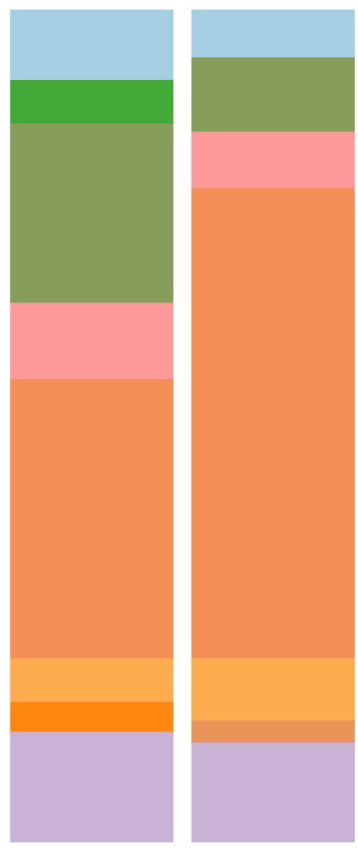

Phylum

Acidobacteria
Actinobacteria
Alphaproteobacteria
Bacteroidetes
Betaproteobaceria
Chloroflexi
Cyanobacteria
Deltaproteobacteria
Firmicutes
Gammaproteobacteria
Other
Patescibacteria
Planctomycetes
Spirochaetes

Acidobacteria

Actinobacteria

Alphaproteobacteria

Bacteroidetes

Betaproteobaceria

Chloroflexi

Cyanobacteria

Deltaproteobacteria

Firmicutes

Gammaproteobacteria

Spirochaetes

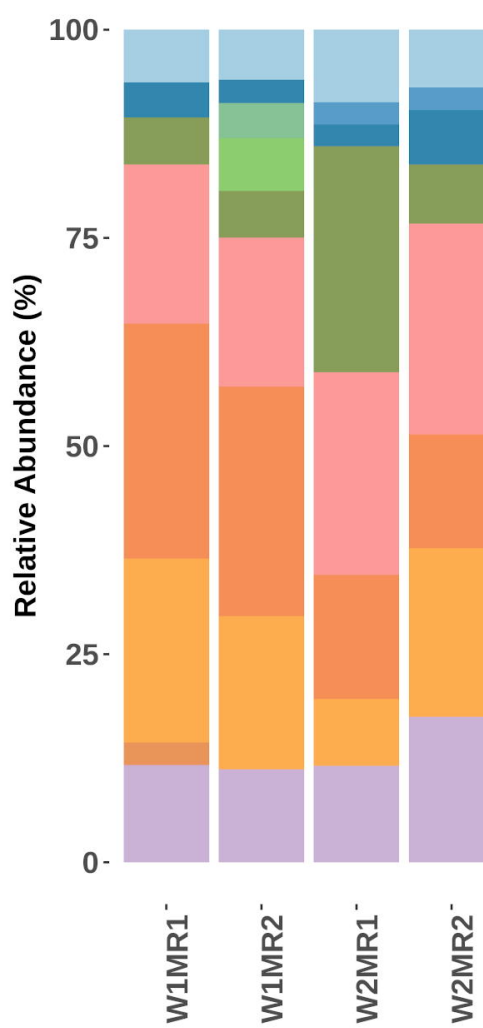

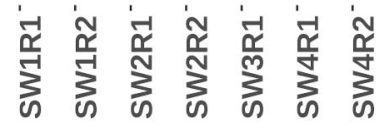

ญ

\section{Family}

Burkholderiaceae Chitinophagaceae

Flavobacteriaceae Lactobacillaceae Leuconostocaceae Limnotrichaceae Methylococcaceae Methylophilaceae Microbacteriaceae Moraxellaceae Other

Rhodobacteraceae Rhodocyclaceae Sphingomonadaceae Unclassified

\section{Sample}


ASV39 Streptococcaceae Lactococcus ASV37 Leuconostocaceae Weissella ASV35 Burkholderiaceae Unclassified ASV31 Moraxellaceae EnhydrobacterASV26 Lactobacillaceae Lactobacillus ASV25 Leuconostocaceae Weissella ASV24 Phycisphaeraceae CL500-3 ASV23 Burkholderiaceae Sphaerotilus ASV22 Unclassified Unclassified ASV21 Saprospiraceae UnclassifiedASV20 Microbacteriaceae Candidatus_AquilunaASV17 Unclassified Unclassified ASV15 Limnotrichaceae LimnothrixASV14 Burkholderiaceae MassiliaASV13 Flavobacteriaceae Flavobacterium ASV12 Sphingomonadaceae Novosphingobium ASV11 Microbacteriaceae Candidatus_AquilunaASV10 Sphingomonadaceae Unclassified ASv09 Chitinophagaceae Terrimonas ASV08 Flavobacteriaceae Flavobacterium ASV07 Burkholderiaceae HydrogenophagaASV06 Rhodobacteraceae Rhodobacter ASV05 Burkholderiaceae Comamonas ASV04 Unclassified Unclassified ASV03 Rhodobacteraceae Unclassified ASV02 Methylococcaceae Methylococcus ASv01 Methylophilaceae Methylobacillus

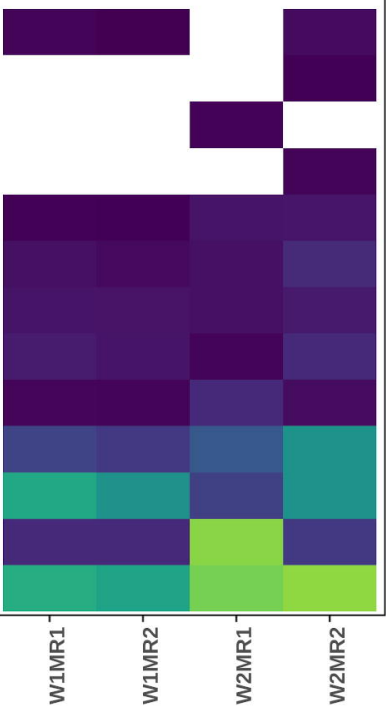

Subsuperficial

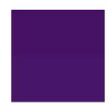




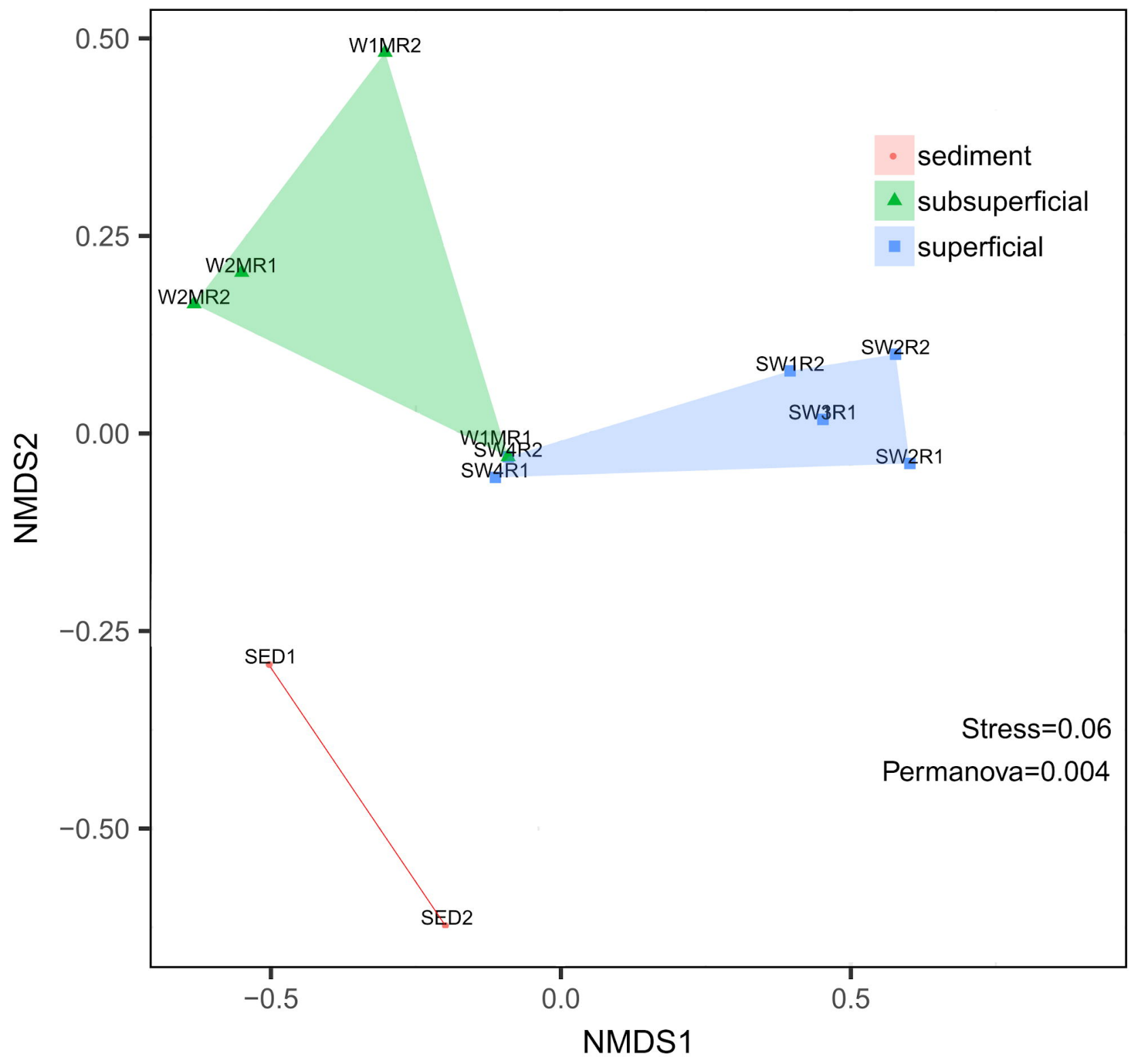




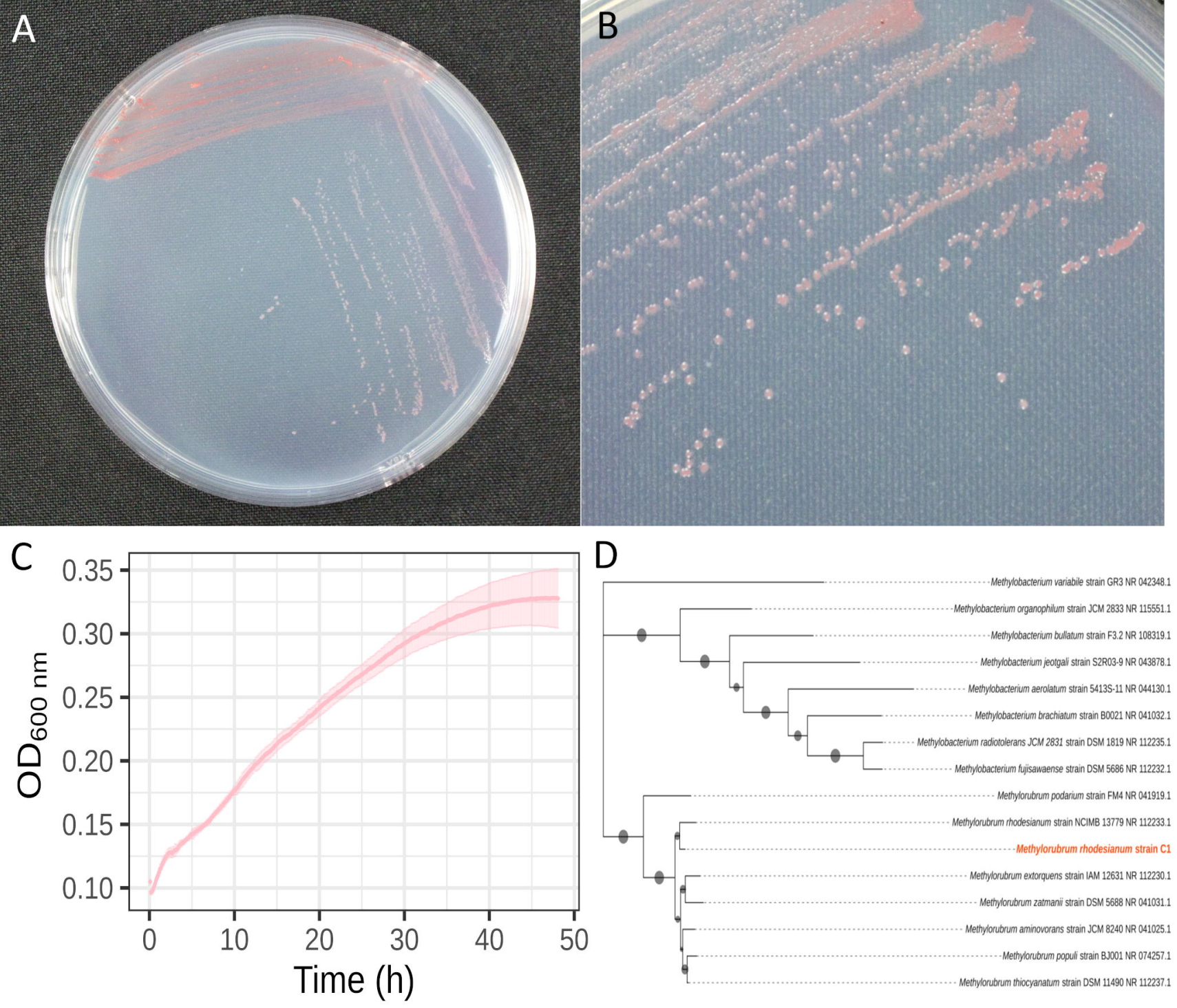




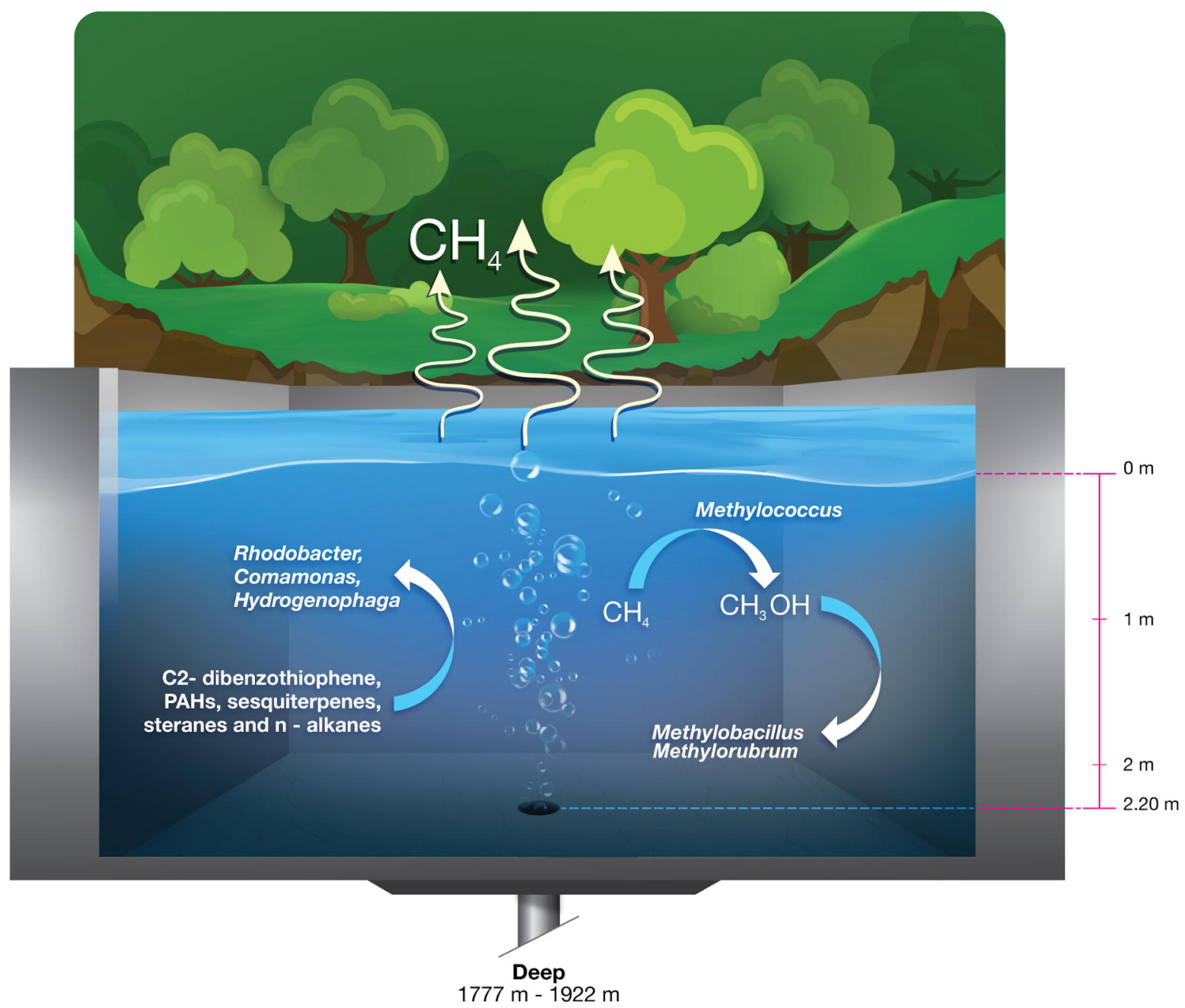

